\title{
ACLIMATIZAÇÃO E CRESCIMENTO DE PLÂNTULAS DE MIRTILEIRO 'CLIMAX' MICROPROPAGADAS EM FUNÇÃO DO SUBSTRATO E DA COBERTURA PLÁSTICA ${ }^{1}$
}

\author{
TÂNIA REGINA PELIZZA² ${ }^{2}$ CLÁUDIA ROBERTA DAMIANI ${ }^{3}$, ANDREA DE ROSSI RUFATO ${ }^{4}$, \\ LUANA BORGES AFFONSO ${ }^{5}$, FERNANDO JOSÉ HAWERROTH ${ }^{6}$, MÁRCIA WULFF SCHUCH ${ }^{7}$
}

RESUMO-Este trabalho foi realizado com o objetivo de avaliar a aclimatização e o crescimento de plântulas micropropagadas de mirtileiro (Vaccinium ashei) cv. Climax, em função do substrato e da cobertura plástica, durante os meses de abril a dezembro de 2008. Foram utilizados três substratos (casca de arroz carbonizada + Húmus Fértil ${ }^{\circledR}$, Plantmax ${ }^{\circledR}+$ vermiculita e solo + serragem jovem de Pínus) e dois sistemas de cobertura (com e sem cobertura plástica sobre as plântulas). As plântulas, acondicionadas em sacos plásticos com os respectivos substratos e sistemas de cobertura, permaneceram em casa de vegetação com temperatura controlada, por 30 dias. Após, permaneceram por 60 dias sem controle ambiental e, em seguida, foram transferidas para telado. A partir de 30 dias, foram avaliados a percentagem de sobrevivência e o incremento de altura das plântulas. Ao término do experimento, foi avaliada a massa fresca e seca da parte aérea e da raiz das plântulas. A percentagem de sobrevivência das plântulas de mirtileiro em substrato Plantmax ${ }^{\circledR}+$ vermicu- $^{-}$ lita é igual quando utilizada ou não a cobertura plástica. $O$ uso da cobertura plástica não foi eficiente para incrementar a altura média das plântulas nos substratos Plantmax ${ }^{\circledR}+$ vermiculita e solo + serragem jovem. A maior massa seca de parte aérea foi obtida com o uso de Plantmax ${ }^{\circledR}+$ vermiculita sem cobertura plástica sobre as plântulas. Plantmax ${ }^{\circledR}+$ vermiculita com e sem cobertura plástica proporcionam maior massa seca radicular que os demais substratos e respectivos sistemas de cobertura, porém Plantmax ${ }^{\circledR}+$ vermiculita sem cobertura plástica é superior a Plantmax ${ }^{\circledR}+$ vermiculita com cobertura plástica. De acordo com os resultados obtidos, conclui-se que o melhor substrato e sistema de cobertura para a aclimatização e o crescimento de plântulas de mirtileiro 'Climax' são Plantmax ${ }^{\circledR}+$ vermiculita sem cobertura plástica.

Termos para indexação: Casa de vegetação, cultura de tecidos, cobertura plástica, micropropagação, Vaccinium ashei.

\section{ACCLIMATIZATION AND GROWTH OF MICROPROPAGATED BLUEBERRY PLANTS 'CLÍMAX' ACCORDING SUBSTRATE AND PLASTIC COVERING}

\begin{abstract}
This study aimed to evaluate the acclimatization and growth of micropropagated blueberry plants (Vaccinium ashei) cv. Climax according to substrate and plastic covering, from April to December 2008. Three substrates (carbonized rice hull + Húmus Fértil $^{\circledR}$, Plantmax $^{\circledR}+$ vermiculite and soil + young sawdust of Pinus) and two covering systems (with or without plastic covering on plants) were used. Plants were put into plastic bags with the respective substrates and covering systems and then stayed in greenhouse at controlled temperature during 30 days. Following this, they were placed without environmental control for 60 days, and then transferred to a screenhouse. After 30 days, it was measured the surviving percentage and the increment of plant height. At the experiment conclusion fresh and dry weight of aerial part and root of the plants were measured. The surviving percentage of blueberry plants in Plantmax ${ }^{\circledR}+$ vermiculite did $^{2}$ not show difference when comparing the use or non-use of plastic covering. The use of plastic covering was not efficient to increase plant height when using the substrates Plantmax ${ }^{\circledR}+$ vermiculite and soil + young

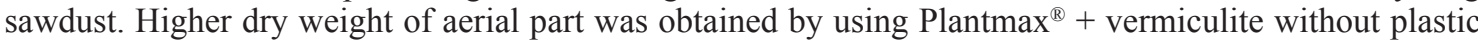
covering on plants. Plantmax ${ }^{\circledR}+$ vermiculite with or without plastic covering promoted drier weight of root than other substrates independent of the covering; however, Plantmax ${ }^{\circledR}+$ vermiculite without plastic covering is superior to Plantmax ${ }^{\circledR}+$ vermiculite with no covering. According to the results, the best substrate and covering system to the acclimatization and growth of blueberry plants 'Climax' are Plantmax ${ }^{\circledR}+$ vermiculite $^{2}$ without plastic covering.
\end{abstract}

Index terms: Greenhouse, tissue culture, plastic covering, micropropagation, Vaccinium ashei.

\footnotetext{
'(Trabalho 162-10). Recebido em: 19-07-2010. Aceito para publicação em: 21-12-2010. Parte de trabalho integrante de Tese de Doutorado do primeiro autor.

${ }^{2} \mathrm{Eng}^{\mathrm{a}}$. Agr ${ }^{\mathrm{a}}$, Dra , Bolsista PRODOC/CAPES, UDESC/CAV, Lages-SC . E-mail: trp_mestagro@hotmail.com

${ }^{3}$ Bióloga, Dra., Profa . Universidade Federal da Grande Dourados (UFGD), Dourados-MS. E-mail: claudami2004@yahoo.com.br

${ }^{4} \mathrm{Eng}^{\mathrm{a}}$. Agr ${ }^{\mathrm{a}}$, Dra., Pesquisadora - EMBRAPA/CNPUV, Vacaria-RS. E-mail: andrea@cnpuv.embrapa.br

${ }^{5}$ Eng $^{\mathrm{a}}$. Agr ${ }^{\mathrm{a}}$, Doutoranda em Sistemas de Produção Agrícola Familiar (SPAF), UFPEL/FAEM, Pelotas-RS. E-mail: luanaffonso@yahoo.com.br

${ }^{6}$ Eng. Agr., Dr., Pesquisador, Embrapa Agroindústria Tropical, Fortaleza-CE. E-mail: fernando@cnpat.embrapa.br

${ }^{7} E^{2}{ }^{\mathrm{a}}$. Agr ${ }^{\mathrm{a}}$, Dra., Prof. do Depto. de Fitotecnia, FAEM/UFPEL, Pelotas-RS. E-mail: marciaws@ufpel.tche.br
} 


\section{INTRODUÇÃO}

O mirtileiro (Vaccinium spp.) é uma espécie frutífera cujos centros de origem são a Europa e América do Norte, locais onde este fruto tem grande importância econômica (RASEIRA, 2006). Apesar de ainda incipiente, a produção brasileira do mirtileiro apresenta grande potencial para expansão. Para que isso ocorra, há a necessidade da disponibilização comercial de mudas de qualidade.

A micropropagação tem sido utilizada para a obtenção de mudas de qualidade. São inúmeras as vantagens de seu uso, porém o custo final é elevado (SCHUCH; ERIG, 2005). Para reduzir o custo e o tempo de permanência em laboratório, uma alternativa é o enraizamento ex vitro. Posteriormente, realiza-se a aclimatização das plântulas retirandoas de uma condição heterotrófica (laboratório) e adaptando-as a uma condição autotrófica (casa de vegetação) (ZIMMERMAN, 1988).

A etapa da aclimatização das plântulas é uma fase crítica e limitante no processo da micropropagação. Esse processo deve ser progressivo de forma que as plântulas não sofram estresse ou venham à morte devido às mudanças de ambiente (GRATTAPAGLIA; MACHADO, 1998). Vários trabalhos já foram conduzidos com aclimatização de plantas frutíferas (HOFFMANN et al., 2001; ERIG et al., 2004; VILLA et al., 2006), no entanto, na cultura do mirtileiro, os trabalhos são praticamente inexistentes.

Durante a aclimatização, o fornecimento de um ambiente adequado para as plantas, a manutenção do sombreamento e de alta umidade relativa, substrato adequado, controle fitossanitário e nutrição adequada são importantes para a sobrevivência e o desenvolvimento das plantas micropropagadas (SCHUCH; ERIG, 2005).

Durante a fase de aclimatização e crescimento das plantas, é necessário o uso de um meio de sustentação e fornecedor de nutrientes: o substrato. A escolha e o manejo correto do substrato irão afetar a sobrevivência, o crescimento e desenvolvimento das plantas, sendo de suma importância o uso de um bom substrato para a obtenção final de mudas de qualidade (BACKES; KÄMPF, 1991).

Assim sendo, conduziu-se este trabalho com o objetivo de avaliar a aclimatização e o crescimento de plântulas micropropagadas de mirtileiro (Vaccinium ashei) cv. Climax, em diferentes substratos e sistemas de cobertura.

\section{MATERIAL E MÉTODOS}

O trabalho foi conduzido em casa de vegetação e telado pertencentes ao Departamento de Fitotecnia da Faculdade de Agronomia Eliseu Maciel da Universidade Federal de Pelotas, durante o período de abril a dezembro de 2008. Em abril de 2008, explantes de mirtileiro da cv. Climax (Vaccinium ashei Reade), enraizados ex vitro em substrato comercial Plantmax ${ }^{\circledR}$, com aproximadamente $2,5 \mathrm{~cm}$ de altura, foram acondicionados em sacos de polietileno preto, tamanho $10 \times 15 \mathrm{~cm}$, contendo diferentes substratos. Em seguida, estes foram acondicionados em bandejas plásticas, o que tornou mais adequada a montagem das parcelas experimentais, onde, sobre elas, de acordo com o tratamento, foi colocado ou não plástico como cobertura. O plástico utilizado era de pvc e transparente. Utilizaram-se 3 substratos: casca de arroz carbonizada + Húmus Fértil ${ }^{\circledR}$ (1:1

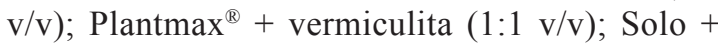
serragem jovem de Pínus (1:1 v/v) e dois sistemas de cobertura: com e sem cobertura plástica. $\mathrm{O}$ solo, um Planossolo predominante na região, foi retirado da camada superficial de uma área agrícola da Universidade e, em seguida, foi peneirado para uso. As plântulas permaneceram em casa de vegetação com controle de temperatura, em $25^{\circ} \mathrm{C} \pm 2$, por 30 dias. Após, as plântulas foram transferidas para casa de vegetação e permaneceram por 60 dias sem controle de temperatura. As temperaturas média, máxima e mínima e as umidades relativas do ar média, máxima e mínima observadas durante este período foram, respectivamente, para o mês de junho, de $15,05^{\circ} \mathrm{C}$; $21,60{ }^{\circ} \mathrm{C} ; 11,05{ }^{\circ} \mathrm{C}$ e $85,32 \% ; 91,91 \% ; 56,10 \%$, e para o mês de julho foram de $15,77^{\circ} \mathrm{C} ; 22,79^{\circ} \mathrm{C}$ e $11,88^{\circ} \mathrm{C}$ e $86,60 \%$; $94,05 \%$ e $59,05 \%$. Aos 90 dias, as plântulas, sem cobertura plástica, foram transferidas para telado em madeira, coberto por tela de sombreamento preta, com $30 \%$ de sombreamento, confeccionada em polietileno de alta densidade e equipado com sistema de irrigação por nebulização, onde permaneceram até os 210 dias. As alterações de ambiente, realizadas lentamente, foram efetuadas a fim de oferecer às plântulas de mirtileiro condições mais adequadas para suportarem o processo de aclimatização.

Neste período, foram efetuadas leituras de temperatura e umidade relativa do ar no local, cujos valores médios do período foram, para temperaturas média, máxima e mínima e umidades relativas do ar média, máxima e mínima, de $19,70^{\circ} \mathrm{C} ; 24,34^{\circ} \mathrm{C}$ e $12,95^{\circ} \mathrm{C}$ e $72,36 \% ; 97,08 \%$ e $49,31 \%$. A irrigação por nebulização foi acionada, a cada hora, por $2 \mathrm{~h} 30$. Porém, como o $\mathrm{pH}$ normal da água de irrigação estava 
próximo a 6,0, quinzenalmente adicionava-se água a pH 5,0 com auxílio de regador. A partir da entrada das plântulas no telado, iniciou-se aplicação quinzenal de solução nutritiva composta por sulfato de amônio (12 $\%$ ), potássio (10\%), magnésio (10\%), ureia (35\%) e ácido fosfórico (10\%). Durante a aclimatização, efetuou-se irrigação manual com pulverizador, com $\mathrm{pH}$ da água igual a 5,0, de acordo com a necessidade das plântulas. Efetuou-se leitura do $\mathrm{pH}$ dos substratos em laboratório de rotina, cujos valores observados para casca de arroz carbonizada + Húmus Fértil ${ }^{\circledR}$ foi

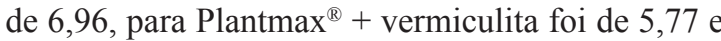
para Solo + serragem jovem de Pínus foi de 6,04.

$\mathrm{O}$ delineamento experimental utilizado foi o inteiramente casualizado, em esquema fatorial $3 \times 2$, sendo 3 substratos e 2 sistemas de cobertura (com e sem cobertura plástica), dispostos em parcelas subdivididas no tempo, com 4 repetições de 8 plântulas em cada repetição. A percentagem de plântulas sobreviventes foi avaliada mensalmente, a partir dos 30 dias. As medidas de altura das plântulas, realizadas com o auxílio de régua graduada, iniciaram aos 60 dias, e, a partir de então, determinou-se o incremento de altura de plântulas até os 210 dias. No tempo total de avaliação (210 dias), não estão acrescidas as fases da micropropagação, que correspondem a aproximadamente 60 dias. Para a determinação da massa seca do sistema radicular e da parte aérea das plântulas, foram coletadas todas as plântulas do experimento. As mesmas foram acondicionadas em sacos de papel e secas em estufa com circulação de ar forçado por 72 horas, à temperatura de $65^{\circ} \mathrm{C}$. Em seguida, foram pesadas em balança analítica. Os dados obtidos foram submetidos à análise de variância, e as médias, comparadas entre si pelo teste de Tukey $(P<0,05)$ através do programa estatístico Winstat (MACHADO; CONCEIÇÃO, 2003). Quando necessário, efetuou-se transformação dos dados através de arcosseno de $\mathrm{x} / 100^{1 / 2}$.

\section{RESULTADOS E DISCUSSÃO}

A análise de variância evidenciou interação entre os fatores substratos x sistemas de cobertura (com e sem cobertura plástica), em função do tempo de avaliação para a variável percentagem de sobrevivência de plântulas. Aos 30 dias de avaliação, período em que foi oferecido às plântulas de mirtileiro controle de temperatura do ar, o uso de casca de arroz carbonizada + Húmus Fértil ${ }^{\circledR}$ sem cobertura plástica já havia reduzido significativamente o número de plântulas sobreviventes $(37,5 \%)$ e chegou aos 60 dias com todas as plântulas mortas. A partir dos 60 dias, o mesmo substrato com cobertura plástica já se diferia dos demais e, ao final do experimento (210 dias), resultou no menor percentual de plântulas sobreviventes $(3,1 \%)$ (Tabela 1$)$.

Embora a casca de arroz carbonizada seja um material que proporciona boas condições físicas ao substrato devido à maior porosidade (MEDEIROS, 1998), drenagem rápida da água e boa aeração (KÄMPF, 2005), e esteja disponível em grande quantidade na região, é, ao mesmo tempo, um material levemente alcalino (MEDEIROS, 1998; KÄMPF, 2005). O Húmus Fértil ${ }^{\circledR}$ é um substrato que apresenta alto percentual de umidade e apresenta como valor de pH 6,8. A associação de casca de arroz carbonizada + Húmus Fertil ${ }^{\circledR}$ apresenta valor de $\mathrm{pH}$ igual a 6,9, ou seja, formam um substrato levemente alcalino, o que, para plântulas de mirtileiro, não é adequado, pois estas adaptam-se melhor aos materiais com $\mathrm{pH}$ do solo ácido. Tais características possivelmente tenham sido responsáveis por afetar negativamente a sobrevivência das plântulas de mirtileiro.

Aos 90 dias de avaliação, o uso do substrato Plantmax $^{\circledR}+$ vermiculita sem cobertura plástica apresentou menor percentual de plântulas sobreviventes que solo + serragem jovem sem cobertura plástica, o que não havia ocorrido até o momento (Tabela 1). Porém, Plantmax ${ }^{\circledR}+$ vermiculita com e sem cobertura plástica foram iguais entre si durante todos os períodos avaliados. O substrato comercial Plantmax $^{\circledR}$ tem como vantagem a uniformidade da composição química e física. Por suas características, é o substrato recomendado para a fase de aclimatização de plantas micropropagadas (HOFFMANN et al., 2001). Segundo Kämpf (2005), a vermiculita oferece boa aeração e alta capacidade de retenção de água, além de baixo peso, e não dissemina doenças (HOFFMANN et al., 2005), o que é possível de ocorrer quando se faz uso do solo sem a devida esterilização. Possivelmente pelas características citadas, de ambos os substratos, obteve-se boa sobrevivência das plântulas. A eficiência da vermiculita também pode ser comprovada através de resultados de sua comercialização, pois, segundo Ferraz et al. (2005), a vermiculita, de origem mineral, e a turfa, de origem vegetal, são os substratos mais utilizados mundialmente.

Solo + serragem jovem apresentaram alto percentual de plântulas sobreviventes, no entanto, neste substrato sem cobertura plástica, $25 \%$ das plântulas morreram após estarem aclimatizadas e já estarem no telado (aos 180 e 210 dias) (Tabela 1). O solo, recurso natural mais facilmente disponível para uso, é um substrato que apresenta pouca drenagem quando utilizado sob nebulização e exige 
desinfestação, pois pode ser fonte de disseminação de doenças (HOFFMANN et al., 2005). A serragem de Pínus, ou de outra planta qualquer, é facilmente encontrada na região e pode ser adquirida gratuitamente. O inconveniente do uso deste material, de acordo com observações realizadas neste trabalho, é que, juntamente com o solo utilizado (solo da região - Planossolo, caracterizado por apresentar má drenagem, baixa soma de bases e baixos teores de matéria orgânica), resulta em um substrato compacto e com pouca drenagem, o que dificultou a sobrevivência e o crescimento da planta. Em função da não esterilização do solo, ocorreu a formação de colônias de fungos saprófitos no substrato Solo + serragem jovem. Possivelmente, tal fator tenha sido o principal responsável pela mortalidade de $25 \%$ das plântulas no telado, no qual plântulas que não utilizaram cobertura plástica se mostraram mais sensíveis a tal situação, enquanto plântulas que foram submetidas ao uso da cobertura, foram mais resistentes.

Em plantas micropropagadas de portaenxerto de macieira 'Marubakaido', Hoffmann et al. (2001), comparando os substratos Plantmax ${ }^{\circledR}$, vermiculita, solo+areia $(1: 1 \mathrm{v} / \mathrm{v})$, composto orgânico+areia $(1: 1 \mathrm{v} / \mathrm{v})$ e solo+composto orgânico+areia (2:2:1 v/v), não verificaram diferenças na sobrevivência das mesmas, quando aclimatizadas em casa de vegetação com nebulização intermitente, temperatura em torno de $30^{\circ} \mathrm{C}$, umidade relativa do ar em torno de $93 \%$ e sombreamento parcial, com tela de sombreamento (50\%). De acordo com Villa et al. (2006), é possível obter até $92 \%$ de sobrevivência, aos 100 dias de aclimatização de amoreira-preta 'Ébano' micropropagada, pré-aclimatizada com abertura de frascos por 3 dias e aclimatizada em bandejas plásticas com o uso de Plantmax ${ }^{\circledR}$. Já para mudas de marmeleiro 'MC' e 'Adams', micropropagadas e aclimatizadas em garrafas plásticas transparentes, a percentagem de sobrevivência foi satisfatória para os substratos Plantmax ${ }^{\circledR}$ e Plantmax ${ }^{\circledR}+$ vermiculita (ERIG et al., 2004). Erig e Schuch (2004) obtiveram $65 \%$ de sobrevivência de mudas de marmeleiro cultivar MC aclimatizadas em substrato solo + Plantmax $^{\circledR}$, em copos plásticos dentro de bandejas fechadas com vidro, após 30 dias.

De acordo com o substrato e o tipo de sistema de cobertura utilizado, ocorre morte das plântulas de mirtileiro com o avanço no tempo de aclimatização e crescimento das mesmas (Tabela 1). Segundo Marin e Gella (1988), uma queda drástica na sobrevivência de plantas de Prunus cerasus ocorre em torno dos 14 dias após o início da aclimatização. Carvalho et al. (2008) verificaram diminuição de aproximadamente $40 \%$ na sobrevivência de plantas de mirtileiro ao final de 120 dias de aclimatização. De acordo com Marin e Gella (1988), esse fenômeno pode ser causado pela baixa eficiência na troca do metabolismo heterotrófico/mixotrófico (com dependência total ou parcial de uma fonte externa de carbono) para o metabolismo autotrófico do carbono (com dependência total da fotossíntese), pois, para Pospíšilová et al. (1999), em condições de casa de vegetação, a irradiância é muito maior e a umidade do ar muito inferior às condições de que as plantas dispunham na sala de crescimento, o que contribui para a morte das mesmas. Para que isso não ocorra, é importante que as plantas, quando passam para uma condição ex vitro, sejam expostas durante algumas semanas a uma progressiva redução na umidade do ar (BOLAR et al., 1998) e gradativo aumento de radiação.

Houve interação entre substrato x sistema de cobertura (com e sem cobertura plástica) em função do tempo de avaliação para o incremento de altura das plântulas de mirtileiro. Dos 60 aos 90 dias, não houve diferença entre substratos e, tampouco, entre os sistemas de cobertura (Tabela 2). Nesse período, que compreende parte da fase em que as plântulas se encontravam sem controle de temperatura, observouse baixa temperatura média do ar. Aliado a isso, ocorreu nesse período baixa radiação solar incidente, $210 \mathrm{cal}^{\mathrm{cm}} \mathrm{cm}^{-2}$.dia ${ }^{-1}$ (Estação Agroclimatológica de Pelotas, 2009). Tais condições são desfavoráveis para o crescimento das plantas, pois afetam a realização da fotossíntese, com prejuízos para a produção de fotoassimilados (ANDRIOLO, 1999). Segundo Marenco e Lopes (2009), plantas expostas a alta luminosidade absorvem íons (nutrientes) mais rapidamente do que aquelas mantidas em condições de baixa irradiância, pois estas alocam menos fotoassimilados para as raízes.

A partir do período 60-120 dias, houve diferenças entre os sistemas de cobertura para o substrato Plantmax $^{\circledR}+$ vermiculita quanto ao incremento médio de altura de planta, em que o maior incremento se deu sem o uso da cobertura plástica. Plantmax ${ }^{\circledR}+$ vermiculita destacam-se sobre os demais substratos, em que as diferenças são mais pronunciadas quando não se utiliza cobertura plástica sobre as plântulas (Tabela 2). Embora o pH deste substrato fosse de 5,9, a vermiculita, que compõe este substrato, apresenta elevada porosidade e boa retenção de umidade (HOFFMANN et al., 2005), o que, juntamente com as qualidades do Plantmax $^{\circledR}$, acredita-se que tenha contribuído para a formação de um bom substrato, e assim possibilitou às plântulas maior incremento em altura.

A presença de uma camada de condensação espessa, formada nos materiais de cobertura, pode reduzir em até $50 \%$ a transmissividade da energia 
solar (ANDRIOLO, 1999). Em função do exposto, acredita-se que este tenha sido um fator determinante que influenciou no crescimento das plântulas em condição de uso da cobertura plástica, já que tal situação foi verificada neste trabalho.

$\mathrm{Na}$ aclimatação de amoreira-preta cv. Ébano, Villa et al. (2006) verificaram maior crescimento de parte aérea das plântulas quando utilizado Plantmax ${ }^{\circledR}$ como substrato. O mesmo foi verificado por Chaves et al. (2006) e também com resultado semelhante para o uso associado do Plantmax ${ }^{\circledR}$ com vermiculita, na avaliação do crescimento da parte aérea de plântulas de Physalis, aclimatizadas em bandejas alveoladas com 128 células, em telado protegido com sombrite e sem nebulização. Augusto et al. (2006) verificaram que, para a aclimatação de plantas micropropagadas de amoreira-preta cv. Brazos, aclimatizadas em bandejas de poliestireno em túnel plástico, há maior crescimento das plantas quando comparado às condições de câmara de nebulização. Maciel et al. (2002) praticamente não observaram diferenças quanto à altura de porta-enxerto de macieira 'Marubakaido' micropropagado quando utilizaram diferentes substratos em avaliações realizadas dos 30 aos 90 dias, em diferentes ambientes de aclimatação. Neste mesmo trabalho, os autores recomendam como melhor ambiente para as plantas a permanência de 20 dias na sala de aclimatização (sala de crescimento) e 10 dias na câmara de nebulização antes de serem colocadas em casa de vegetação. Ledo et al. (2007) não observaram diferenças no comprimento da parte aérea de plântulas de coqueiro-anão-verde (Cocos nucifera L.), quando testaram areia lavada e pó de casca de coco seco + areia lavada como substrato, aos 30 dias, quando aclimatadas em telado com 50\% de sombreamento e cobertas nos primeiros sete dias com sacos de plástico transparente. No entanto, aos 120 dias, o comprimento da parte aérea das plântulas foi superior em substrato composto por pó de casca de coco seco + areia lavada.

Houve interação entre substrato x sistema de cobertura (com e sem cobertura plástica) para as variáveis massa seca da parte aérea e massa seca do sistema radicular de plântulas de mirtileiro 'Climax'. Com a utilização da cobertura plástica, não houve diferenças para a variável massa seca da parte aérea em quaisquer dos substratos utilizados (Tabela 3). Porém, quando não se utilizou cobertura plástica sobre as plântulas, o substrato Plantmax ${ }^{\circledR}+$ vermiculita sobressai-se aos demais. A massa seca do sistema radicular das plântulas é maior em substrato Plantmax $^{\circledR}+$ vermiculita, em ambos os sistemas de cobertura, comparativamente aos demais substratos. Tal resultado demonstra a capacidade que estas con- dições proporcionadas às plântulas têm em favorecer o acúmulo de reservas nas mesmas. Esta condição possivelmente contribua para o momento em que as plântulas forem levadas a campo, pois acredita-se que plântulas de mirtileiro com maior sistema radicular e maior massa vegetal tenham maiores chances de sobreviverem e por adaptarem-se ao novo ambiente. Para Plantmax ${ }^{\circledR}+$ vermiculita e solo + serragem, a massa seca da parte aérea e do sistema radicular é maior no tratamento sem cobertura plástica sobre as plântulas. A massa seca da parte aérea e do sistema radicular não diferiu para o substrato casca de arroz carbonizada + Húmus Fértil ${ }^{\circledR}$ quanto ao uso ou não da cobertura plástica.

Em plantas micropropagadas de porta-enxerto de macieira 'Marubakaido', Maciel et al. (2002) não verificaram diferenças para massa seca de raiz quando utilizado terra roxa estruturada + vermicomposto bovino (1:1 - v:v) e terra roxa estruturada + casca de arroz carbonizada (1:1 - v:v) aos 30 e 90 dias após enraizamento ex vitro. Segundo Wagner Júnior et al. (2004), a matéria seca da parte aérea de plantas micropropagadas de porta-enxerto de ameixeira 'Mariana 2614' é maior quando utilizado casca de arroz carbonizada + Plantmax ${ }^{\circledR}$ como substrato, em relação ao uso de casca de arroz carbonizada + solo + esterco durante a aclimatização, realizada em casa de vegetação com túnel baixo de plástico e sombrite sobre as plantas. Porém, a matéria seca de raiz não é afetada pelo uso dos diferentes substratos. Villa et al. (2006) observaram ser o substrato Plantmax ${ }^{\circledR}$ o melhor dentre vários outros testados para a aclimatização de plantas micropropagadas de amoreira-preta cv. Ébano. Os mesmos autores verificaram maior massa seca e fresca da parte aérea e radicular das plantas, maior comprimento da parte aérea e de raízes em substrato Plantmax ${ }^{\circledR}$ utilizado isoladamente. Ristow et al. (2009) verificaram maior massa seca do sistema radicular e da parte áerea de plantas micropropagadas de mirtileiro 'Georgiagem' quando utilizaram como substrato acícula de Pínus + solo. No entanto, Ferri (2008) observou que o uso do substrato constituído por $70 \%$ de serragem $+20 \%$ de fibra de coco $+10 \%$ de esterco bovino é o que proporciona maior matéria seca da parte aérea e radicular de plantas micropropagadas de mirtileiro nas cultivares Climax e Aliceblue (Rabbiteye), enquanto, para 'O'Neal' e 'Georgiagem' (Highbush), melhores resultados, para as mesmas variáveis, foram observados em substrato constituído por $70 \%$ de casca de arroz carbonizada $+20 \%$ de serragem + $10 \%$ de esterco bovino. 
TABELA 1 - Médias da percentagem de sobrevivência de plântulas de mirtileiro 'Climax' em diferentes substratos e sistemas de cobertura durante 210 dias de avaliação. UFPEL/FAEM, Pelotas, 2009.

\begin{tabular}{|c|c|c|c|}
\hline \multirow[b]{2}{*}{$\begin{array}{l}\text { Sistema de } \\
\text { cobertura } \\
\text { plástica }\end{array}$} & \multicolumn{3}{|c|}{ Sobrevivência (\%) } \\
\hline & $\begin{array}{l}\text { Casca de arroz } \\
\text { carbonizada }+ \\
\text { Húmus Fértil }^{\circledR}\end{array}$ & $\begin{array}{c}\text { Plantmax }^{\circledR} \\
\text { +vermiculita }\end{array}$ & $\begin{array}{c}\text { Solo+serragem } \\
\text { jovem }\end{array}$ \\
\hline & \multicolumn{3}{|c|}{30 dias } \\
\hline Com cobertura & $100,0 \mathrm{Aa}^{*}$ & $100,0 \mathrm{Aa}$ & $100,0 \mathrm{Aa}$ \\
\hline \multirow[t]{2}{*}{$\underline{\text { Sem cobertura }}$} & $37,5 \mathrm{Bb}$ & $87,5 \mathrm{Aa}$ & $100,0 \mathrm{Aa}$ \\
\hline & \multicolumn{3}{|c|}{60 dias } \\
\hline Com cobertura & $62,5 \mathrm{Ba}$ & $96,8 \mathrm{Aa}$ & $100,0 \mathrm{Aa}$ \\
\hline \multirow[t]{2}{*}{ Sem cobertura } & $0,0 \mathrm{Bb}$ & $78,1 \mathrm{Aa}$ & $96,8 \mathrm{Aa}$ \\
\hline & \multicolumn{3}{|c|}{90 dias } \\
\hline Com cobertura & $40,6 \mathrm{Ba}$ & $93,7 \mathrm{Aa}$ & $100,0 \mathrm{Aa}$ \\
\hline \multirow[t]{2}{*}{ Sem cobertura } & $0,0 \mathrm{Cb}$ & $68,7 \mathrm{Ba}$ & $96,8 \mathrm{Aa}$ \\
\hline & \multicolumn{3}{|c|}{120 dias } \\
\hline Com cobertura & $3,1 \mathrm{Ba}$ & $90,6 \mathrm{Aa}$ & $100,0 \mathrm{Aa}$ \\
\hline \multirow[t]{2}{*}{ Sem cobertura } & $0,0 \mathrm{Ca}$ & $68,7 \mathrm{Ba}$ & $96,8 \mathrm{Aa}$ \\
\hline & \multicolumn{3}{|c|}{150 dias } \\
\hline Com cobertura & $3,1 \mathrm{Ba}$ & $90,6 \mathrm{Aa}$ & $96,8 \mathrm{Aa}$ \\
\hline \multirow[t]{2}{*}{ Sem cobertura } & $0,0 \mathrm{Ca}$ & $68,7 \mathrm{Ba}$ & $96,8 \mathrm{Aa}$ \\
\hline & \multicolumn{3}{|c|}{180 dias } \\
\hline Com cobertura & $3,1 \mathrm{Ba}$ & $87,5 \mathrm{Aa}$ & $96,8 \mathrm{Aa}$ \\
\hline \multirow[t]{2}{*}{ Sem cobertura } & $0,0 \mathrm{Ba}$ & $68,7 \mathrm{Aa}$ & $75,0 \mathrm{Ab}$ \\
\hline & \multicolumn{3}{|c|}{210 dias } \\
\hline Com cobertura & $3,1 \mathrm{Ba}$ & $87,5 \mathrm{Aa}$ & $96,8 \mathrm{Aa}$ \\
\hline Sem cobertura & $0,0 \mathrm{Ba}$ & $68,7 \mathrm{Aa}$ & $75,0 \mathrm{Ab}$ \\
\hline
\end{tabular}

* Letras maiúsculas na linha e minúsculas na coluna, dentro de cada tempo de avaliação, não diferem estatisticamente entre si, pelo teste de Tukey, a $1 \%$ de probabilidade de erro.

TABELA 2- Médias do incremento de altura (cm) de plântulas de mirtileiro 'Climax' em diferentes substratos e sistemas de cobertura dos 60 aos 210 dias de avaliação. UFPEL/FAEM, Pelotas, 2009.

\begin{tabular}{|c|c|c|c|}
\hline \multirow{2}{*}{$\begin{array}{l}\text { Sistemas de } \\
\text { cobertura } \\
\text { plástica }\end{array}$} & \multicolumn{3}{|c|}{ Incremento médio de altura de planta $(\mathrm{cm})$} \\
\hline & $\begin{array}{c}\text { Casca de arroz carbonizada }+ \\
\text { Húmus Fértil }^{\circledR}\end{array}$ & Plantmax $^{\circledR}+$ vermiculita & Solo+serragem jovem \\
\hline & \multicolumn{3}{|c|}{$60-90$ dias } \\
\hline Com cobertura & $0,90 \mathrm{Aa}^{* *}$ & $0,49 \mathrm{Aa}$ & $0,28 \mathrm{Aa}$ \\
\hline \multirow{2}{*}{ Sem cobertura } & $0,00 \mathrm{Aa}$ & 2,53 Aa & $0,22 \mathrm{Aa}$ \\
\hline & \multicolumn{3}{|c|}{$60-120$ dias } \\
\hline Com cobertura & $0,83 \mathrm{Aa}$ & $0,99 \mathrm{Ab}$ & $0,33 \mathrm{Aa}$ \\
\hline \multirow{2}{*}{ Sem cobertura } & $0,00 \mathrm{Ba}$ & 5,33 Aa & $0,63 \mathrm{Ba}$ \\
\hline & \multicolumn{3}{|c|}{$60-150$ dias } \\
\hline Com cobertura & $1,59 \mathrm{Ba}$ & $4,67 \mathrm{Ab}$ & $2,51 \mathrm{ABa}$ \\
\hline \multirow[t]{2}{*}{$\underline{\text { Sem cobertura }}$} & $0,00 \mathrm{Ba}$ & $11,85 \mathrm{Aa}$ & $2,55 \mathrm{Ba}$ \\
\hline & \multicolumn{3}{|c|}{$60-180$ dias } \\
\hline Com cobertura & $1,64 \mathrm{Ba}$ & $6,01 \mathrm{Ab}$ & $1,90 \mathrm{Bb}$ \\
\hline \multirow[t]{2}{*}{ Sem cobertura } & $0,00 \mathrm{Ca}$ & $15,07 \mathrm{Aa}$ & $6,13 \mathrm{Ba}$ \\
\hline & \multicolumn{3}{|c|}{$60-210$ dias } \\
\hline Com cobertura & $2,34 \mathrm{Ba}$ & $6,55 \mathrm{Ab}$ & $1,98 \mathrm{Bb}$ \\
\hline Sem cobertura & $0,00 \mathrm{Ca}$ & $17,20 \mathrm{Aa}$ & 7,79 $\mathrm{Ba}$ \\
\hline
\end{tabular}

* Letras maiúsculas na linha e minúsculas na coluna, dentro de cada tempo de avaliação, não diferem estatisticamente, pelo teste de Tukey, a $1 \%$ de probabilidade de erro. 
TABELA 3 - Médias de biomassa seca de parte aérea e biomassa seca do sistema radicular de plântulas de mirtileiro 'Climax' avaliadas aos 210 dias. UFPEL/FAEM, Pelotas, 2009.

\begin{tabular}{cccc}
\hline $\begin{array}{c}\text { Sistemas de cobertura } \\
\text { plástica }\end{array}$ & $\begin{array}{c}\text { Casca de arroz carbonizada } \\
\text { + Húmus Fértil }\end{array}$ & $\begin{array}{c}\text { Plantmax } \\
\text { vermiculita }\end{array}$ & $\begin{array}{c}\text { Solo+serragem } \\
\text { jovem }\end{array}$ \\
\hline \multicolumn{4}{c}{ Biomassa seca de parte aérea $(\mathrm{g})$} \\
\hline Com cobertura & $0,06 \mathrm{Aa}^{* *}$ & $0,17 \mathrm{Ab}$ & $0,03 \mathrm{Ab}$ \\
Sem cobertura & $0,00 \mathrm{Ca}$ & $1,21 \mathrm{Aa}$ & $0,21 \mathrm{Ba}$ \\
\hline \multicolumn{4}{c}{ Biomassa seca radicular $(\mathrm{g})$} \\
\hline Com cobertura & $0,00 \mathrm{Ca}$ & $0,05 \mathrm{Ab}$ & $0,01 \mathrm{Bb}$ \\
Sem cobertura & $0,00 \mathrm{Ca}$ & $0,28 \mathrm{Aa}$ & $0,04 \mathrm{Ba}$ \\
\hline
\end{tabular}

** Letras maiúsculas na linha e minúsculas na coluna não diferem estatisticamente entre si, pelo teste de Tukey, a $1 \%$ de probabilidade de erro.

\section{CONCLUSÕES}

1-A percentagem de sobrevivência das plântulas micropropagadas de mirtileiro em substrato Plantmax ${ }^{\circledR}+$ vermiculita é igual quando utilizado ou não cobertura plástica. No entanto, quando utilizado cobertura plástica, com esta mistura de substrato, há um incremento da altura média das plântulas.

2-Maior massa seca de parte aérea e do sistema radicular é obtida com o uso de Plantmax ${ }^{\circledR}+$ vermiculita sem cobertura plástica sobre as plântulas.

3-Recomenda-se evitar o uso da casca de arroz carbonizada + Húmus Fértil ${ }^{\circledR}$ para a aclimatização e crescimento de plântulas micropropagadas de mirtileiro.

\section{REFERÊNCIAS}

ANDRIOLO, J. L. Fisiologia das culturas protegidas. Santa Maria: Ed. da UFSM, 1999.

AUGUSTO, C. S. S.; BIASI, L. A.; TELLES, C. A. Enraizamento e aclimatização de plantas micropropagadas de amoreira-preta cv. Brazos. Revista Brasileira de Fruticultura, Jaboticabal, v. 28, n. 3, p. 473-476, 2006.

BACKES, M. A.; KÄMPF, A. N. Substratos à base de composto de lixo urbano para a produção de plantas ornamentais. Pesquisa Agropecuária Brasileira, Brasília, v. 26, n. 4/5 p. 753-758, 1991.

BOLAR, J.P.; NORELLI, J.L.; ALDWINCKLE, H.S.; HANKE, V. An efficient method for rooting and acclimation of micropropagated apple cultivars. HortScience, New York, v. 37, n. 7, p. 1251-1252, 1998.
CARVALHO, G. L.; PELIZZA, T. R.; SOUZA, A. L. K. de; SCHUCH, M. W. Enraizamento ex vitro de cultivares de mirtileiro em diferentes substratos. In: CONGRESSO DE INICIAÇÃO CIENTÍFICA, 18. ENCONTRO DE PÓS-GRADUÇÃO, 11., Pelotas, 2008. Resumos... Pelotas: UFPEL/FAEM, 2008. CD-ROM.

CHAVES, A. DA C.; ERIG, A. C.; SILVA, L. C. DA; SCHUCH, M. W. Aclimatação de plântulas de Physalis peruviana L. Toda Fruta, 2006. Disponível na internet: $<$ http://www.todafruta.com.br/todafruta/ mostra_conteudo.asp?conteudo $=12591>$. Acesso em: 24 ago. 2008.

ERIG, A. C.; SCHUCH, M. W.; CHAVES, A. da C. Enraizamento in vitro e aclimatização de mudas de marmeleiro cvs. Mc e Adams, utilizadas como portaenxerto para a pereira. Scientia Agrária, Curitiba, v. 5, n. 1-2, p. 61-68, 2004.

ESTAÇÃO AGROCLIMATOLÓGICA DE PELOTAS - Capão do Leão. Boletim Agroclimatológico, Pelotas, 2009. Disponível em: $<$ http://www.cpact. embrapa.br/agromet/estacao/boletim.html $>$. Acesso em: 22 out. 2009.

FERRAZ, M. V.; CENTURION, J. F.; BEUTLER, A. N. Caracterização física e química de alguns substratos comerciais. Acta Scientiarum. Agronomy, Maringá, v. 27, n. 2, p. 209-214, 2005.

FERRI, J. Micropropagação e desenvolvimento vegetativo de mirtilo. 2008. 215 f. Dissertação (Mestrado em agronomia, Área de concentração Fruticultura de Clima Temperado) - Faculdade de Agronomia, Universidade Federal de Pelotas, Pelotas, 2008. 
GRATTAPAGLIA, D; MACHADO, M.A. Micropropagação. In: TORRES, A.C.; CALDAS, L.S.; BUSO, J.A. Cultura de tecidos e transformação genética de plantas. Brasília: Embrapa-SPI / Embrapa-CNPH, 1998. v.1, p.183-260.

HOFFMANN, A.; FACHINELlO, J. C.; NACHTIGAL, J. C. Formas de propagação de plantas frutíferas. In: FACHINELLO, J. C. Propagação de plantas frutíferas. Brasília: Embrapa Informação Tecnológica, 2005. p. 45-56.

HOFFMANN, A.; PASQUAL, M.; CHALFUN, N.N.J.; FRÁGUAS, C.B. Efeito de substratos na aclimatização de plantas micropropagadas de portaenxertos de macieira "Marubakaido". Ciência e Agrotecnologia, Lavras, v.25, n.2, p.462-467, 2001.

KÄMPF, A. N. Substrato. In: KÄMPF, A.N. Produção comercial de plantas ornamentais. Guaiba: Agropecuária, 2005. p. 45-72.

LEDO, A. DA S.; GOMES, K. K. P.; BARBOZA, S. B. S. C.; VIEIRA, G. S. S.; TUPINAMBÁ, E. A.; ARAGÃO, W. M. DE. Cultivo in vitro de embriões zigóticos e aclimatação de plântulas de coqueiroanão. Pesquisa Agropecuária Brasileira, Brasília, v. 42, n. 2, p.147-154, 2007.

MACHADO, A. A.; CONCEIÇÃO, A. R. Sistema de análise estatística para Windows: Winstat versão 2.0. Pelotas: UFPel, 2003.

MACIEL, S. da C.; VOLTOLINI, J. A.; PEDROTTI, E. L. Enraizamento ex vitro e aclimatação do portaenxerto de macieira Marubakaido micropropagado. Revista Brasileira de Fruticultura, Jaboticabal, v. 24, n. 2, p. 289-292, 2002.

MARENCO, R. A.; LOPES, N. F. Fisiologia vegetal. Viçosa: UFV, 2009. 486 p.

MARIN, J.A.; GELLA, R. Is dessecation the cause of the poor survival rate in the acclimatization of micropropagated Prunus cerasus L. Acta Horticulturae, Wageningen, n. 230, p.105-112, 1988.
MEDEIROS, C. A. Carbonização da casca de arroz para utilização em substratos destinados à produção de mudas. Pelotas: Embrapa Clima Temperado, 1998. p.1-4. (Circular Técnica, 8).

POSPÍŠILOVÁ, J.; TICHÁ, I.; KADLEČEK, P.; HAISEL, D.; PLZÁKOVÁ, Š. Acclimatization of micropropagated plants to ex vitro conditions. Biologia Plantarum, Praga, v. 42, n. 4, p. 481-497, 1999.

RASEIRA, M.C.B. Descrição da planta, melhoramento genético e cultivares. In: RASEIRA, M.C.B.; ANTUNES, L.E.C. Sistemas de produção: cultivo do mirtilo. Pelotas: Embrapa Clima Temperado, 2006. 99 p.

RISTOW, N. C.; ANTUNES, L. E. C. ; SCHUCH, M. W. ; TREVISAN, R.; CARPENEDO, S. Crescimento de plantas de mirtilo a partir de mudas micropropagadas. Revista Brasileira de Fruticultura, Jaboticabal, v. 31, n. 1, p. 210-215, 2009.

SCHUCH, M. W.; ERIG, A. C. Micropropagação de plantas frutíferas. In: FACHINELLO, J. C.; HOFFMANN, A.; NACHTIGAL, J. C. Propagação de plantas frutíferas. Brasília: Embrapa Informação Tecnológica, 2005. p. 155-173.

VILLA, F.; PASQUAL, M.; ARAÚJO, A. G. de; PIO, L. A. S. Micropropagação da amoreira-preta (Rubus spp.) e efeito de substratos na aclimatização de plântulas. Acta Scientiarum Agronomy, Maringá, v. 28, n. 1, p. 47-53, 2006.

WAGNER JÚNIOR, A.; SILVA, J. O. DA C. E E., SANTOS, C. E. M. DOS; PIMENTEL, L. D.; NEGREIROS, J. R. DA S.; BRUCKNER, C. H. Ácido giberélico no crescimento inicial de mudas de pessegueiro. Ciência e Agrotecnologia, Lavras, v. 32, n. 4, p. 1035-1039, 2008.

ZIMMERMAN, R. H. Micropropagation of woody plants: post tissue culture aspects. Acta Horticulturae, Wageningen, n. 227, p. 489-499, 1988. 